\title{
Effect of Parameters on Soil-Structure Interaction of a Buried Corrugated Steel Arch Bridge
}

\author{
Baodong Liu*, Miaoxin Zhang, Pengfei Li and Zhimao Feng \\ School of Civil Engineering, Beijing Jiaotong University, Beijing, 100044, China
}

\begin{abstract}
Based on an actual corrugated steel plate arch bridge, considering soil-structure interaction, by using the finite element program of ANSYS, a 2-D finite element model was set up to analyze the soil pressure and structural deformation under different load conditions in detail. Since this type of structure relies on the soil-structure interaction to share the load, as the structural parameters have a strong effect on the mechanical characteristics of the structure. So the soil pressure and deformation of the structure were analyzed by changing the parameters, such as the cross-section of corrugated steel plate, the elastic modulus, internal friction angle and Poisson's ratio of the backfill soil. The analysis shows that soilstructure interaction redistributes stress in the surrounding soil and reduces the adverse influence of excessive structural displacement. Results reveal that the stiffness decrease of the corrugated steel plate is positive to the soil-structure interaction and reduces the vertical soil pressure. The increase of elastic modulus of backfill soil is positive with respect to soilstructure interaction and leads to smaller soil pressure to the steel arch. Larger internal friction angle of the backfill soil increases the difference of soil pressure within and outside the span and has slightly negative effect to the soil-structure interaction. Soil with smaller Poisson's ratio has some positive effect in reducing soil pressure to the steel arch.
\end{abstract}

Keywords: Buried corrugated steel arch bridge, Soil-structure interaction, Finite element analysis, Soil pressure.

\section{INTRODUCTION}

A buried corrugated steel arch bridge is constructed in the form of an arch using a corrugated steel plate with backfill soil. The corrugated steel plate and surrounding soil work together to share the load. This type of structure has the advantages of convenient construction and lower maintenance cost, and more adaptable deformation property so vehicles can move smoothly on it. The buried corrugated steel structure is originally built as highway structures in countries that have deserts and permafrost, such as the USA, Canada, North Europe. Now, it is an optimal structure to replace small span bridges and culverts. But In China, the study of such structures is still at an early stage [1-3].

Soil-structure interaction exists between the steel arch and surrounding soil because they are of different stiffnesses. If the deformation of a structure is greater than surrounding soil it is called a flexible structure, otherwise a rigid structure. Some studies show that many parameters influence the soil-structure interaction, but the non-elastic properties of soil are not easily studied. The incremental linear elastic model with elastic modulus $E$ and Poisson's ratio $\mu$ is very popular in numerical analysis of soil engineering. In reference [4], two kinds of stress state, such as an axial compressed member and semi-infinite body under a concentrated force on the surface, were adopted to research the effects of $E$ and $\mu$. One parameter was simply assumed to keep a

Address corresponding to this author at the School of Civil Engineering, Beijing Jiaotong University, Beijing, 100044, China;

Tel: +86-13910296797; Fax: +86-01051687248;

E-mail: baodongliu@vip.sina.com constant and effects of variation of another parameter were analyzed.

Because of the complexity of a buried corrugated steel structure, the use of a mathematical model is difficult without a computer. For this reason, the finite-element (FE) method is commonly used in the numerical analysis of complicated structures; it is fast in speed of operation and can solve difficult problems $[5,6]$. In this paper, using the ANSYS program, a FE model was established and structural performances under different load conditions were analyzed. In addition, the effect of different parameters on soil pressure and deformation are analyzed under changing values of section profile of the corrugated steel plate and the elastic modulus, internal friction angle, and Poisson's ratio of the surrounding soil.

\section{ACTUAL ARCH BRIDGE DESCRIPTION}

An arch bridge of national highway NO.207 in China is the subject of this study. The arch has a span of $7.42 \mathrm{~m}$, the height of its arch is $2.50 \mathrm{~m}$, the width of the pavement is $26 \mathrm{~m}$, and the road is designed with six traffic lanes. The minimum depth of soil cover is $1.8 \mathrm{~m}$ [7]. A cross section of the arch bridge is presented in Fig. (1).

The material of the corrugated steel plate is galvanized steel Q235A with its yield strength and allowable stress of $235 \mathrm{MPa}$ and $140 \mathrm{MPa}$, respectively. The profile of the corrugated steel plate for the arch wall is $400 \mathrm{~mm} \times 180 \mathrm{~mm}$ as shown in Fig. (2). The thickness of the plate is $7 \mathrm{~mm}$. The backfill soil cover is silty sand. The unit weight, internal friction angle, and elastic modulus of soil are $19 \mathrm{kN} / \mathrm{m}^{3}$, 
$30^{\circ}$ and $30 \mathrm{MPa}$, respectively. The backfill is carried out symmetrically during the period of construction.

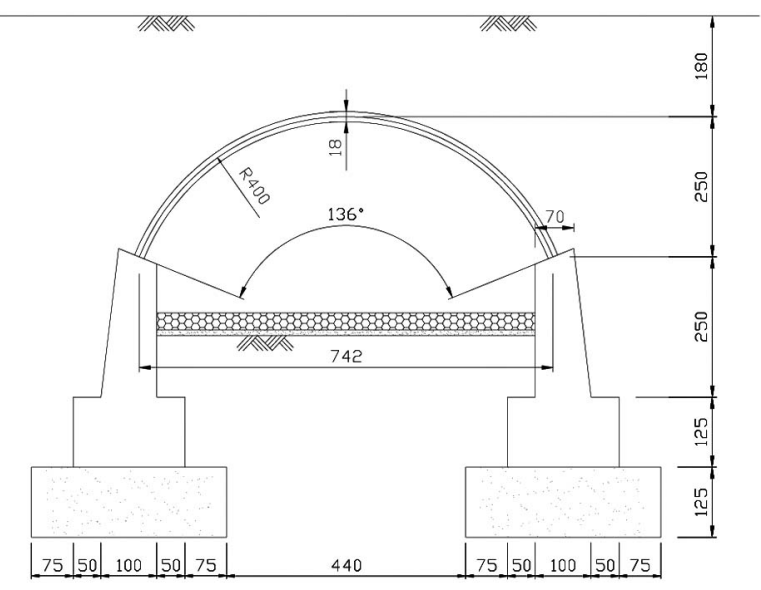

Fig. (1). Cross section of the bridge (cm).

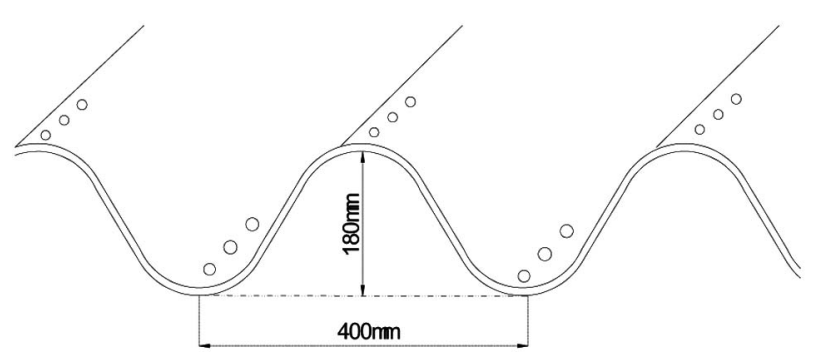

Fig. (2). Profile of corrugated steel plate (mm).

\section{FINITE ELEMENT ANALYSIS MODEL}

Assuming corrugated steel arch bridge is long enough in the longitudinal direction, it is feasible to simplify steel plate of one unit length as plane-strain problem and calculate using a 2-D model [8]. When creating the model, corrugated steel plate can be simplified as flat plate based on the equivalent stiffness principle [9], the moment of inertia and cross section of steel plate per unit length are $34280 \mathrm{~mm}^{4} / \mathrm{mm}$ and $9.733 \mathrm{~mm}^{2} / \mathrm{mm}$; its elastic modulus and unit weight are $2.06 \times 10^{5} \mathrm{MPa}$ and $78.5 \mathrm{kN} / \mathrm{m}^{3}$. There is a pavement layer above the backfill soil layer; thickness of the pavement layer is $0.4 \mathrm{~m}$, the other parameters of two types of layers are shown in Table 1. Beam3 element is utilized for corrugated steel plate unit; plane82 element is adopted for the backfill and pavement layer; add the contact element and introduce coupled nodes for soil-structure interaction. Drucker-Prager yield criterion is used in the backfill layer. The width of the surrounding soil on each side of the arch bridge is 1.5 times of the span $(11.13 \mathrm{~m})$. The finite element analysis model is shown in Fig. (3).

\section{SOIL-STRUCTURE INTERACTION ANALYSIS OF THE BRIDGE}

Relative displacements between corrugated steel arch and surrounding soil have direct influence on the mechanical performance of the structure. A large corrugation type was chosen in the bridge; therefore, the stiffness of steel arch is much larger than soil, so the bridge is a rigid structure. Fig. (4) shows a horizontal path on the crown in the finite element model; calculations such as soil pressure distribution and displacements are based on the path.

In the analysis process, three different load conditions are taken into account: only the weight of soil and arch is called dead load; a static vehicle added on the crown of arch is called vehicle load; a static vehicle added on the right quarter of span to the crown is called deflective load. Here vehicle

Table 1. Parameter Values of Backfill Layer and Pavement Layer

\begin{tabular}{|c|c|c|c|}
\hline Title & Elastic Modulus & Unit Weight & Poisson's Ratio \\
\hline \hline Backfill layer & $15 \mathrm{MPa}$ & $19 \mathrm{kN} / \mathrm{m}^{3}$ & 0.2 \\
\hline Pavement layer & $300 \mathrm{MPa}$ & $25 \mathrm{kN} / \mathrm{m}^{3}$ & 0.3 \\
\hline
\end{tabular}

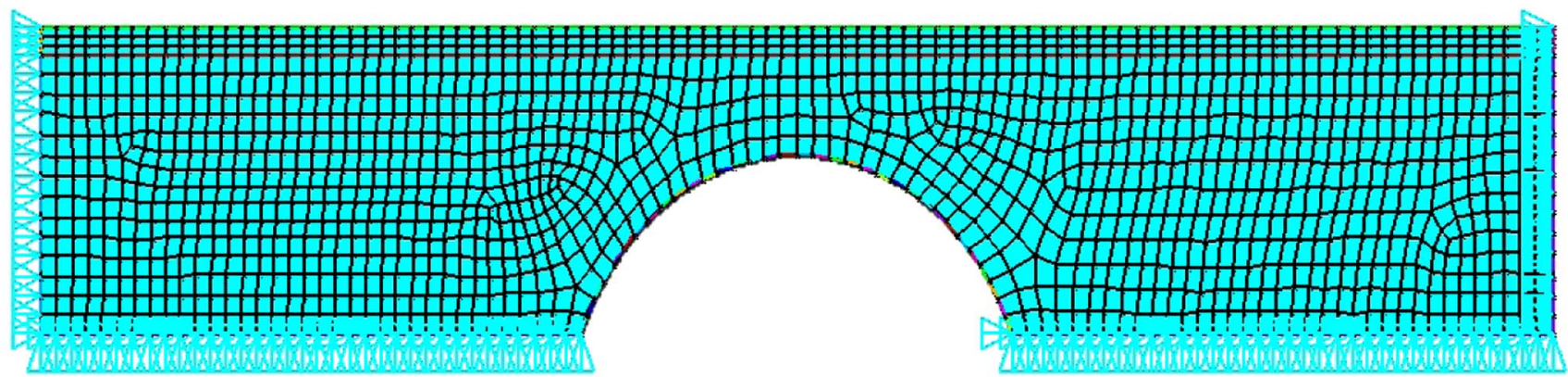

Fig. (3). Finite element analysis model. 


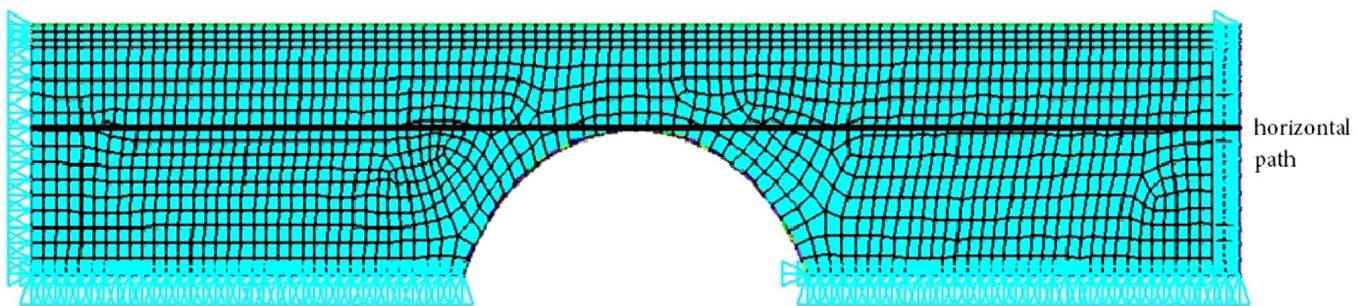

Fig. (4). Horizontal path on the crown.

loads refer to truckloads in reference [10] and calculations follow its rules. The vertical soil pressure distribution and displacements under different load conditions along the horizontal path are shown in Fig. (5 to 7 ).

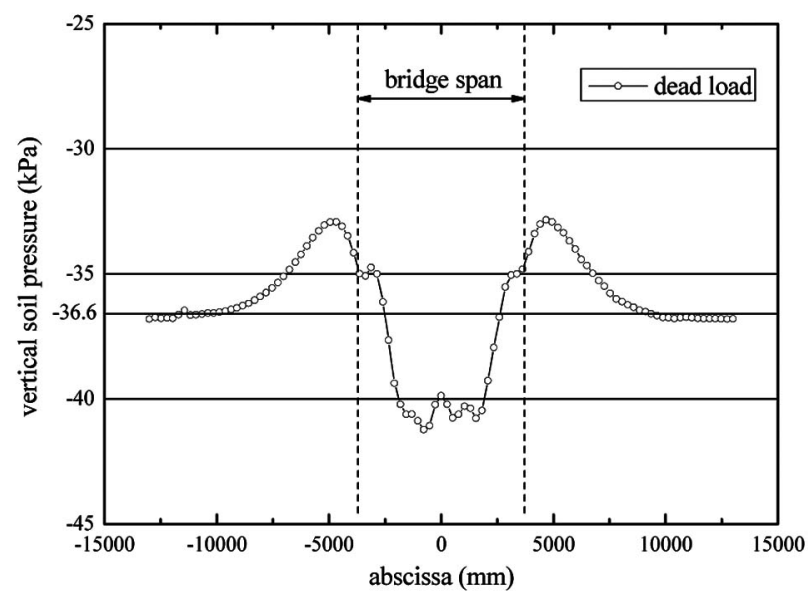

Fig. (5a). Vertical soil pressure under dead load.

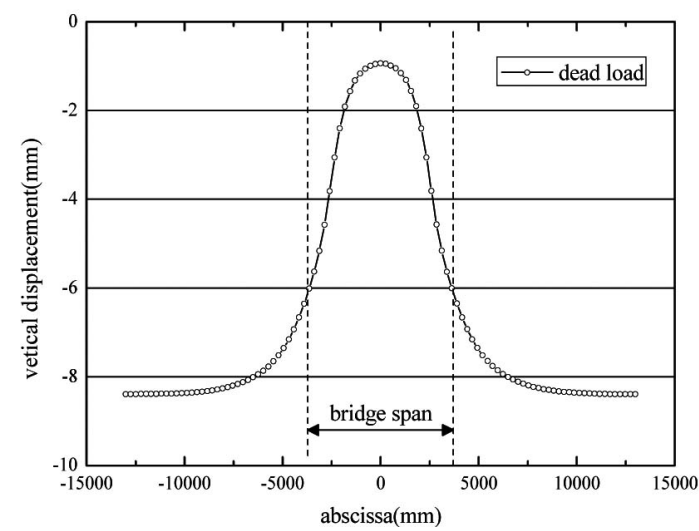

Fig. (5b). Vertical displacement under dead load.

As Fig. (5a) shows, within the range of bridge span, the values of vertical soil pressure are larger than the values in the code $[10](\gamma H=36.6 \mathrm{kPa})$; from mid-span to 1.5 times span, the values of vertical soil pressure are lower than values in the code; beyond 1.5 times span the vertical soil pressure tends to be value in the code. Fig. (5b) shows vertical displacements of steel arch are much smaller than surrounding soils, the result of soil-structure interaction is the vertical soil pressure which steel arch undertakes is larger than the soil weight on it. The soil near besides arch share less soil pressure because of the steel arch shares more soil loads.

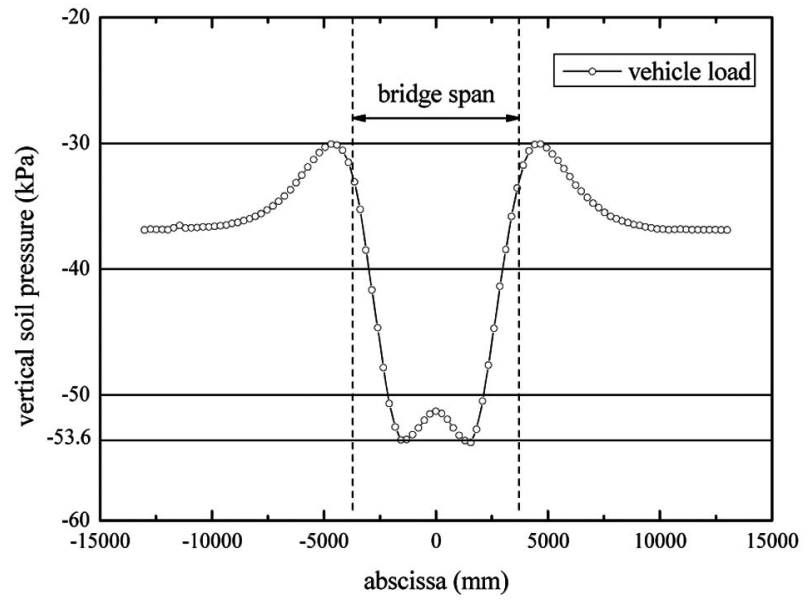

Fig. (6a). Vertical soil pressure under vehicle load.

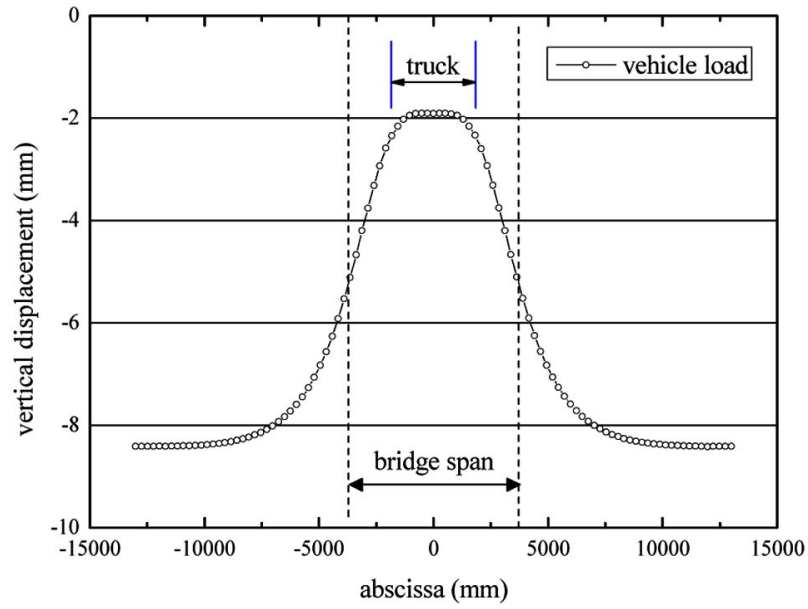

Fig. (6b). Vertical displacement under vehicle load.

As can be seen from Fig. (6a), the values of vertical soil pressure are close to the value in the code [10] $\left(\gamma H+p_{y}=53.6 \mathrm{kN}\right)$ within the bridge span, here $p_{y}$ is the vertical soil pressure which truck load spread to the crown of arch. There is rebound on the crown for the soil pressure; it is slightly less than the peak value. As can be seen from Fig. (6b), the vertical displacements are very close in the scope that vehicle loads spread, so the displacement of the crown is 
the largest and stresses redistribution of surrounding soils which was brought out by soil-structure interaction appears in the range of bridge span.

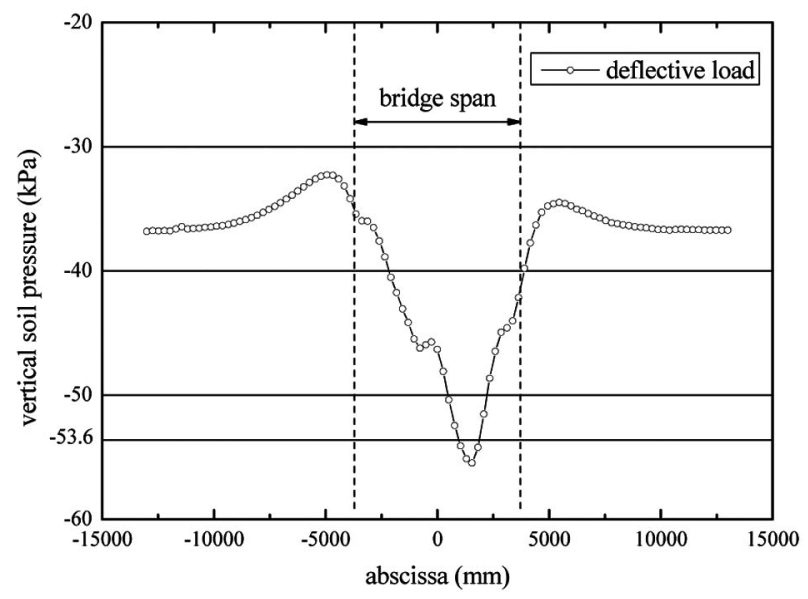

Fig. (7a). Vertical soil pressure under deflective load.

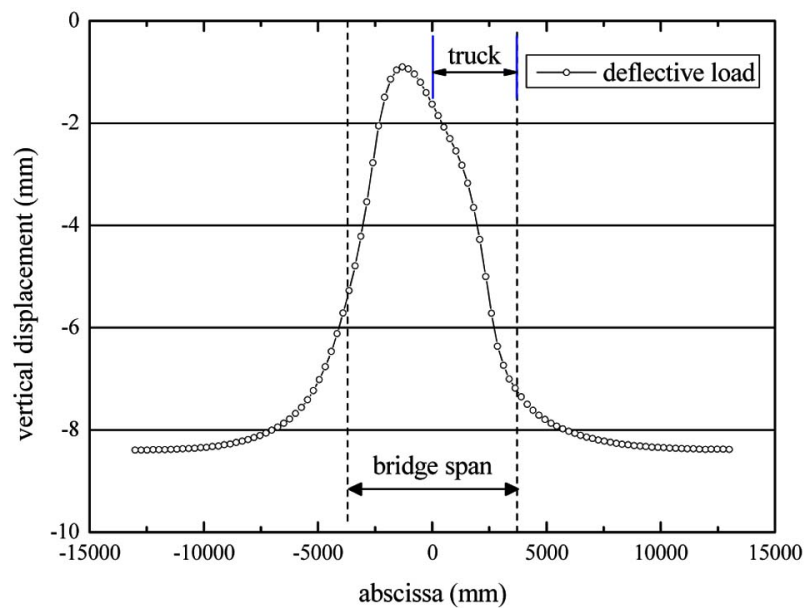

Fig. (7b). Vertical displacement under deflective load.

Under deflective load condition, the peak value of vertical soil pressure shows up at the quarter of the span just under the truck load as shown in Fig. (7a), and it is larger than that in vehicle load condition. As can be seen from Fig. (7b), asymmetric deformation occurs to the structure when there is deflective affection.

\section{EFFECTS OF PARAMETERS ON SOIL-STRUC- TURE INTERACTION}

\section{Effects of the Section Parameters of Corrugated Steel Plate}

To compare the effects of the section parameters of corrugated steel plate on soil-structure interaction, another section profile of $200 \mathrm{~mm} \times 55 \mathrm{~mm} \times 5 \mathrm{~mm}$ is selected. The moments of inertia for the smaller and larger corrugation profile are
$2053.5 \mathrm{~mm}^{4} / \mathrm{mm}$ and $34280.2 \mathrm{~mm}^{4} / \mathrm{mm}$, respectively. As can be seen, the larger corrugation is 17 times as the smaller one, so it has a larger stiffness. The vertical soil pressure distribution and displacements of the two corrugations types under three different load conditions are shown in Fig. (8 to 10).
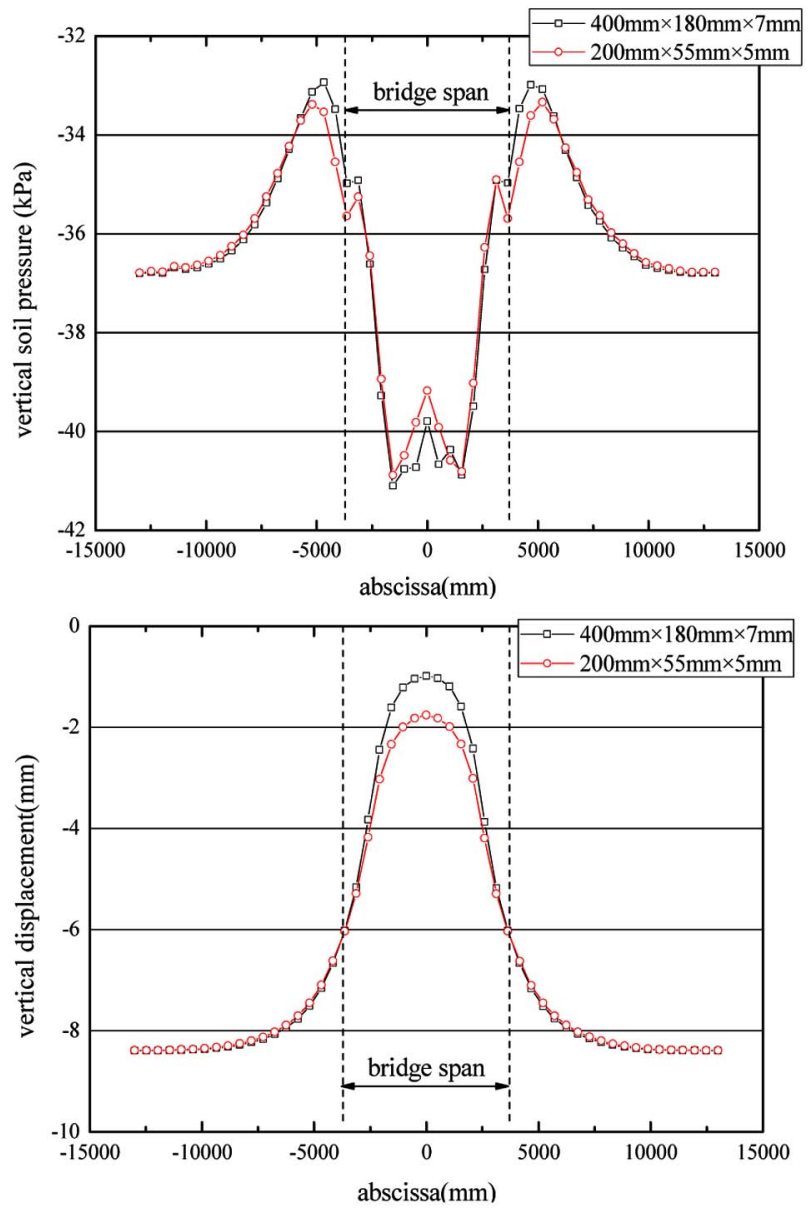

Fig. (8). Vertical soil pressure and displacement of two types under dead load.

As shown in Fig. (8), under dead load, the vertical soil pressure decreases and the soil displacement increases within the span as the stiffness is reduced. Fig. (9) reveals the same rule as Fig. (8), but after the truck load acted, the difference of displacement and vertical soil pressure at mid-span increased. Fig. (10) indicates the reduced range of displacement and vertical soil pressure under deflective load condition becomes larger as the stiffness of corrugated steel plate decreased. The peak value of soil pressure with small stiffness is smaller than that of the vehicle load condition, which is opposite to larger stiffness arch. All the above analysis shows that the stiffness decrease of corrugated steel plate is positive to the soil-structure interaction and reduces the vertical soil pressure. That's because relative displacements between steel arch and adjacent soil decrease with structural stiffness decreasing, which leads to small soil pressure above steel arch. 

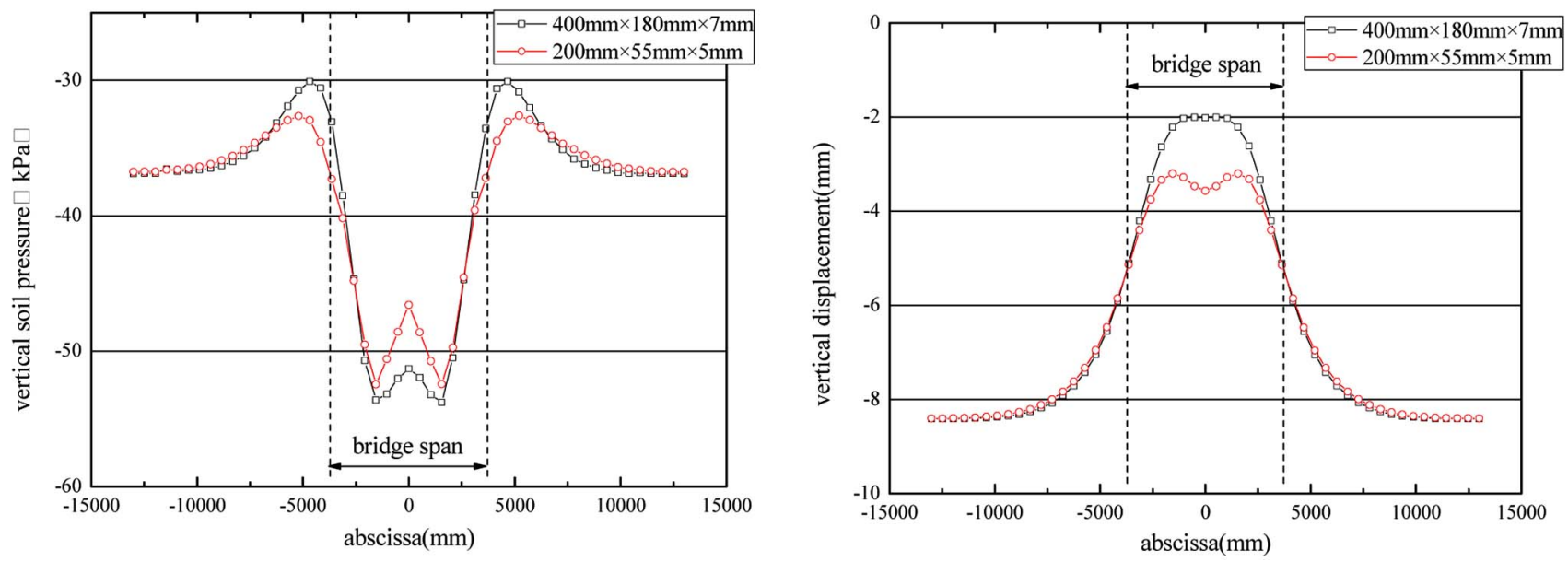

Fig. (9). Vertical soil pressure and displacement of two types under vehicle load.
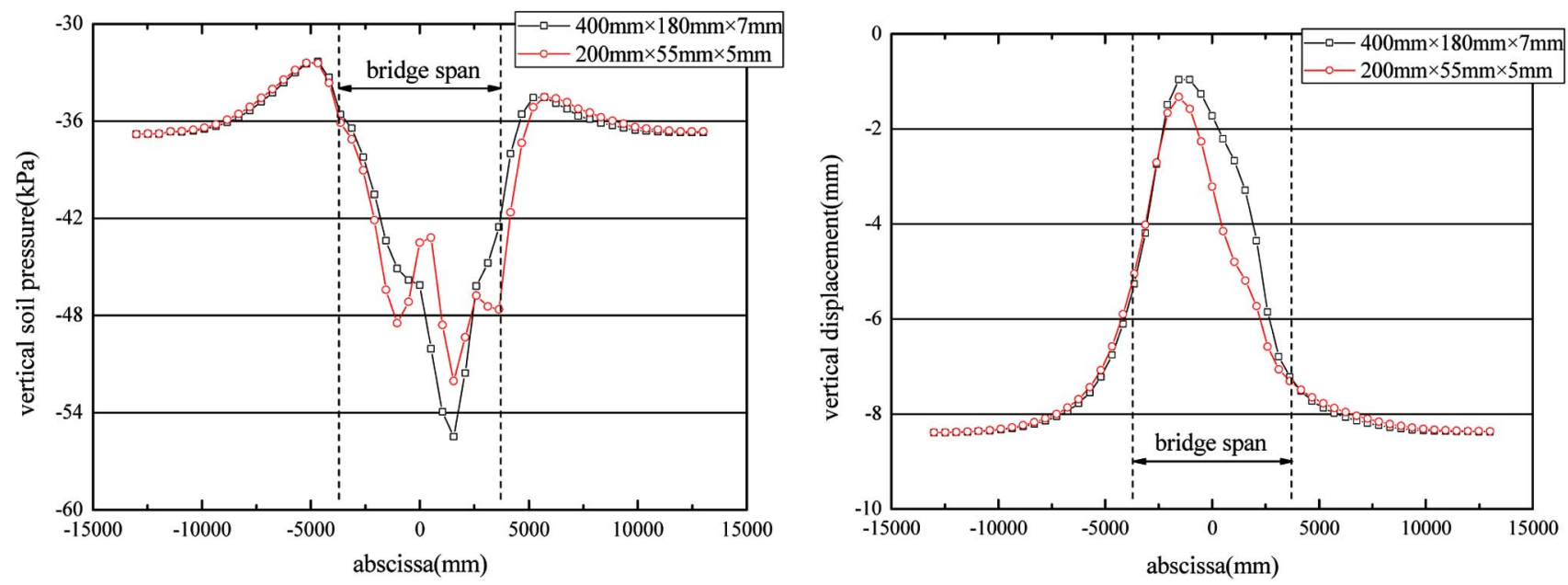

Fig. (10). Vertical soil pressure and displacement of two types under deflective load.
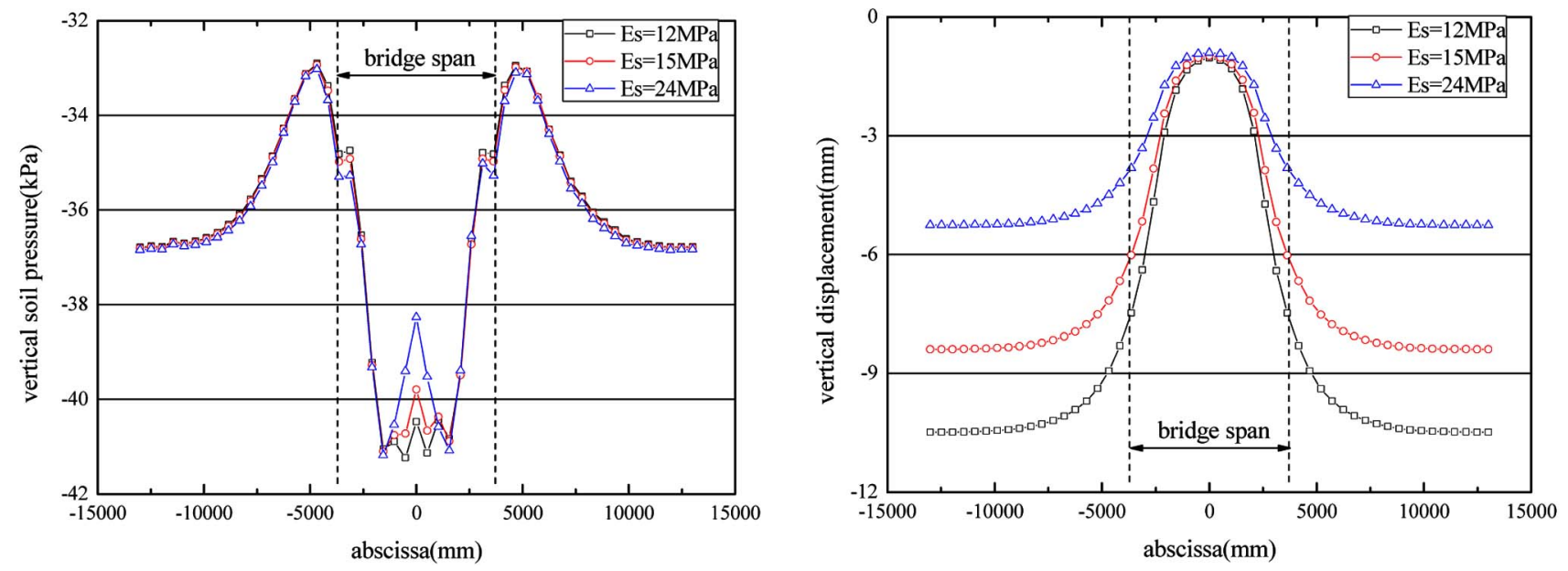

Fig. (11). Vertical soil pressure and displacement of different elastic moduli under dead load.

\section{Effects of the Soil Parameters}

Most soil backfill associated with the buried corrugated steel bridge is sand, requiring it to be backfilled symmetri- cally and compacted, as in table 7.6.1.3 (b) of reference [11]. Soil-structure interaction is greatly affected by different parameters such as soil type, compaction, and other parameters. 
Three important parameters of sand are elastic modulus, internal friction angle, and Poisson's ratio.

To analyze the influence of elastic modulus on soil pressure and displacement, three different values such as $12 \mathrm{MPa}$, $15 \mathrm{MPa}$ and $24 \mathrm{MPa}$ are adopted according to reference [11]. The vertical soil pressure distribution and displacements of three different elastic moduli under three different load conditions are shown in Fig. (11 to 13).

As can be seen from Fig. (11 to 13), the soil displacement is obviously reduced when soil elastic modulus increases. Within the span, change of soil pressure under the dead load is larger than vehicle load. In general, the increase of elastic modulus is positive with respect to soil-structure interaction leading to smaller soil pressure at the steel arch. Decrease of soil displacements leads to small difference of deformation within and outside the span, which is positive in reducing soil pressure within the span.

For different soil backfill, three different internal friction angles conditions are analyzed according to reference [12].
The values are $30^{\circ}, 35^{\circ}$ and $40^{\circ}$. The vertical soil pressure distribution and displacements of three different internal friction angles under three different load conditions are shown in Fig. (14 to 16).

Fig. (14 to 16) reveals that smaller internal friction angle leads to slightly larger soil displacement. A small friction angle promotes easier movement of soil when relative displacement occurs between backfill soil and corrugated steel arch. When deformation difference exists, the weight of soil with large displacement is transferred to soil of small displacement and increase of internal friction angle enhances the transfer effect. As can be seen from Fig. (14 to 16), the difference of soil pressure within and outside the span increases with internal friction angle increasing. Soil with larger internal friction angle has slightly negative effect to the soil-structure interaction.

Poisson's ratio is another soil parameter which can affect soil-structure interaction. The Poisson's ratio of $0.2,0.25$ and 0.3 are compared and analyzed according to reference [13]. The vertical soil pressure distribution and displacements of

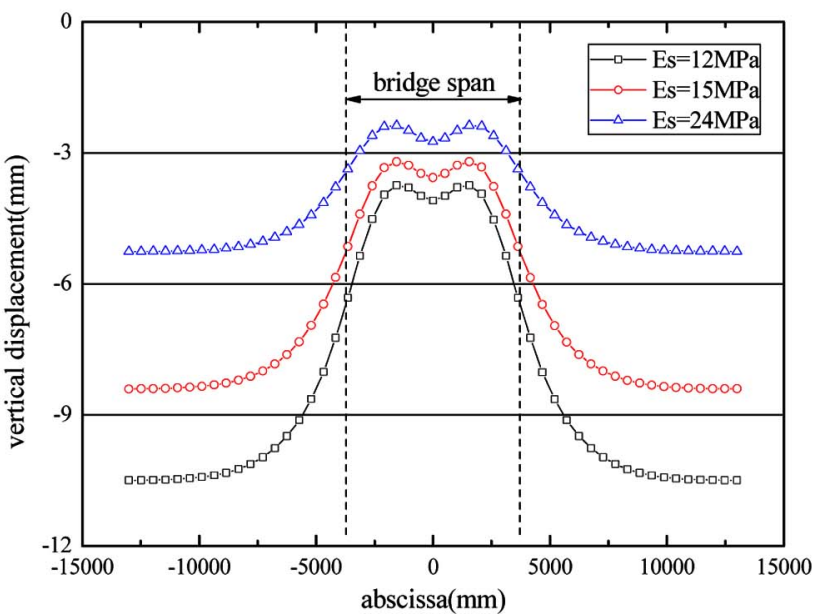

Fig. (12). Vertical soil pressure and displacement of different elastic moduli under vehicle load.
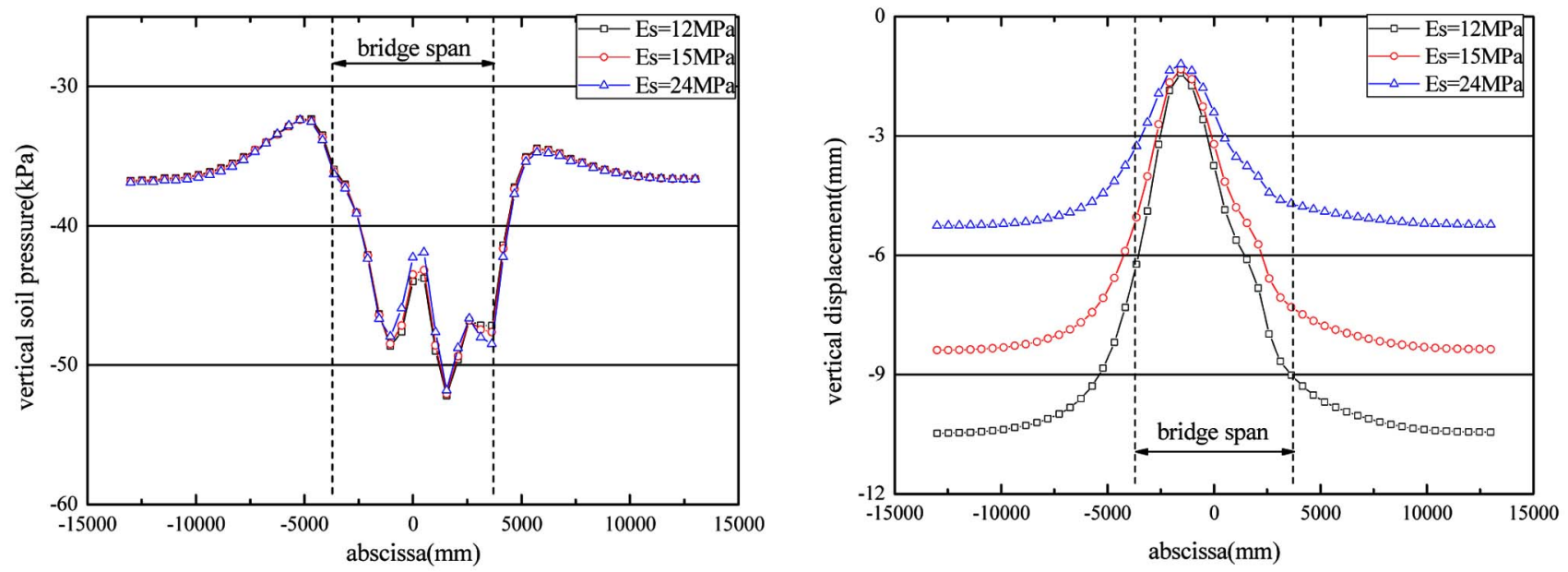

Fig. (13). Vertical soil pressure and displacement of different elastic moduli under deflective load. 

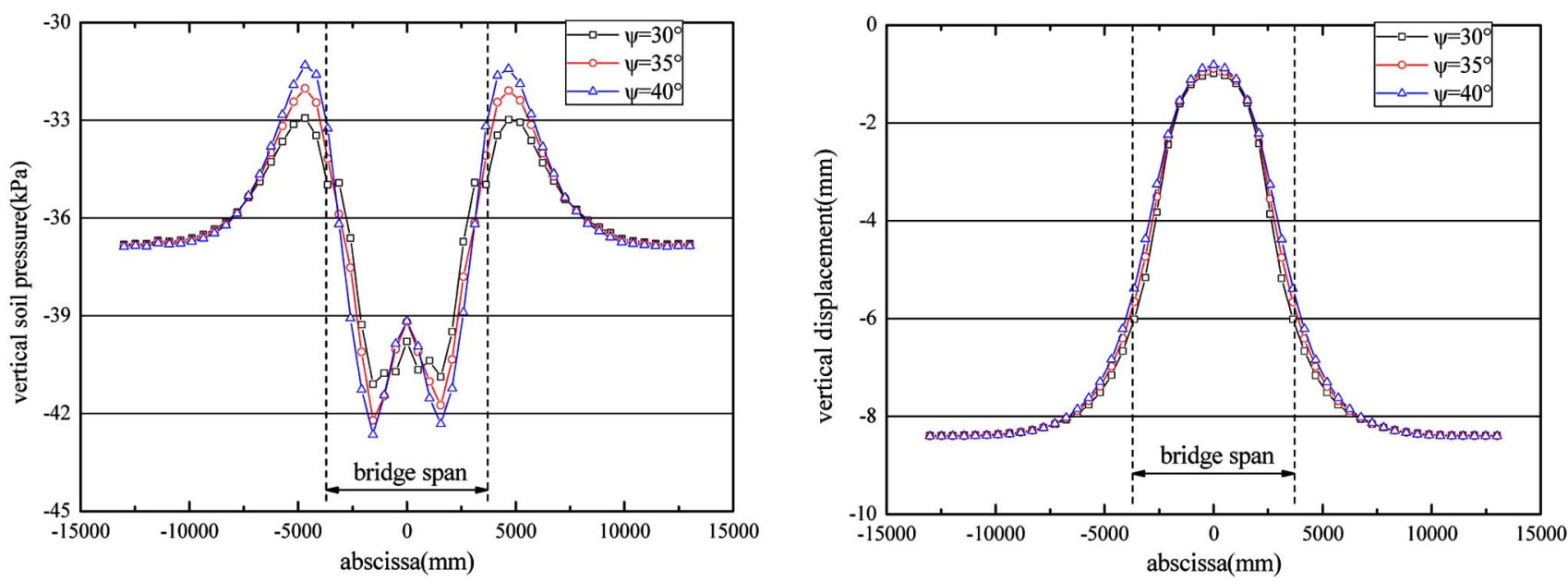

Fig. (14). Vertical soil pressure and displacement of different internal friction angles under dead load.
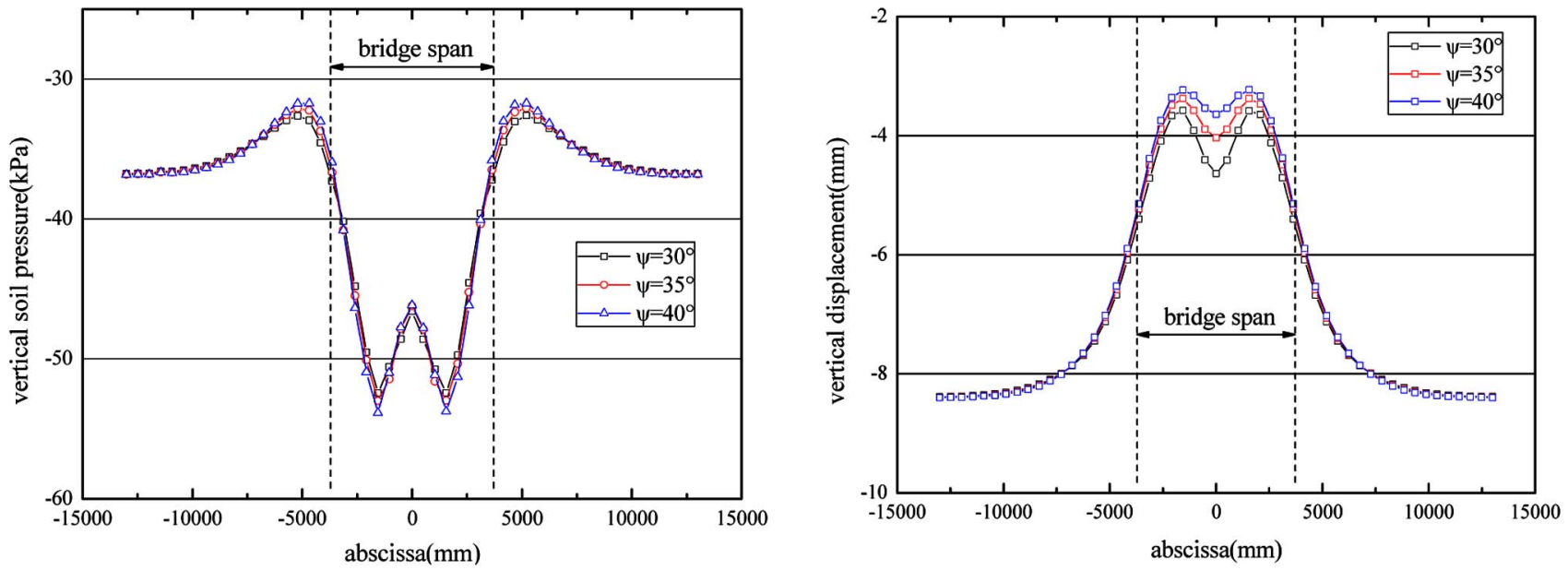

Fig. (15). Vertical soil pressure and displacement of different internal friction angles under vehicle load.
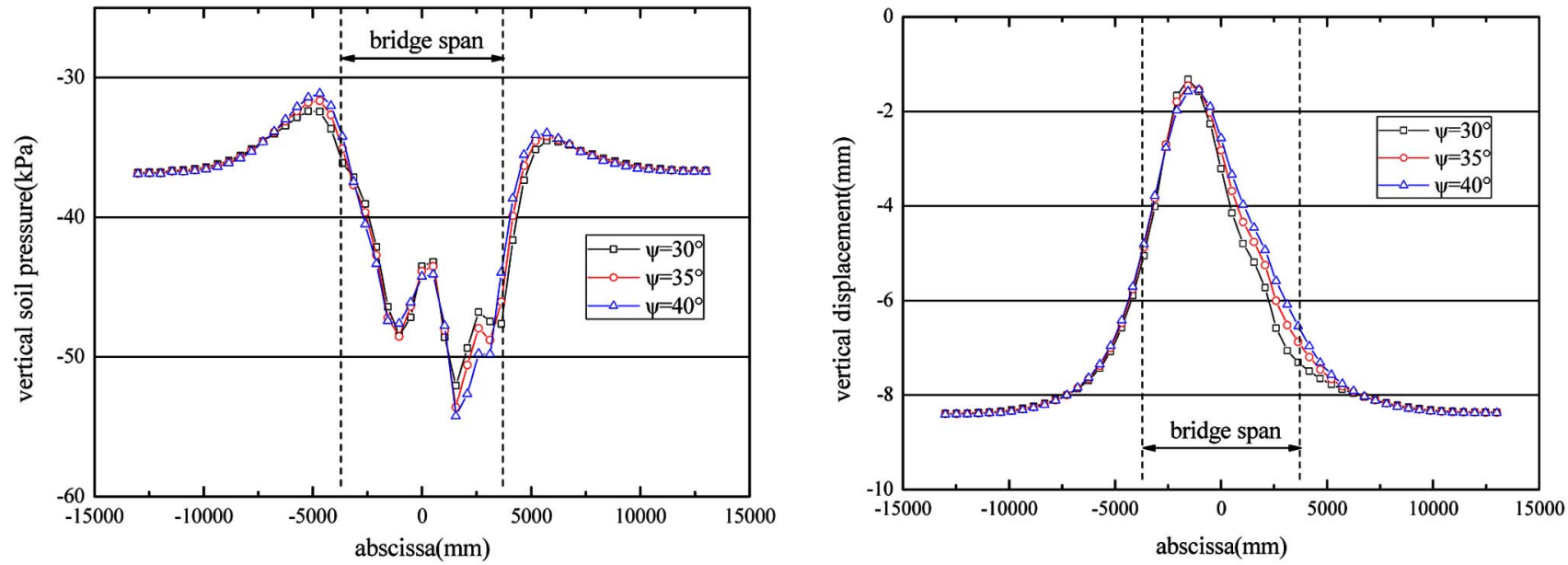

Fig. (16). Vertical soil pressure and displacement of different internal friction angles under deflective load. 
three different Poisson's ratios under three different load conditions are shown in Fig. (17 to $\mathbf{1 9})$.

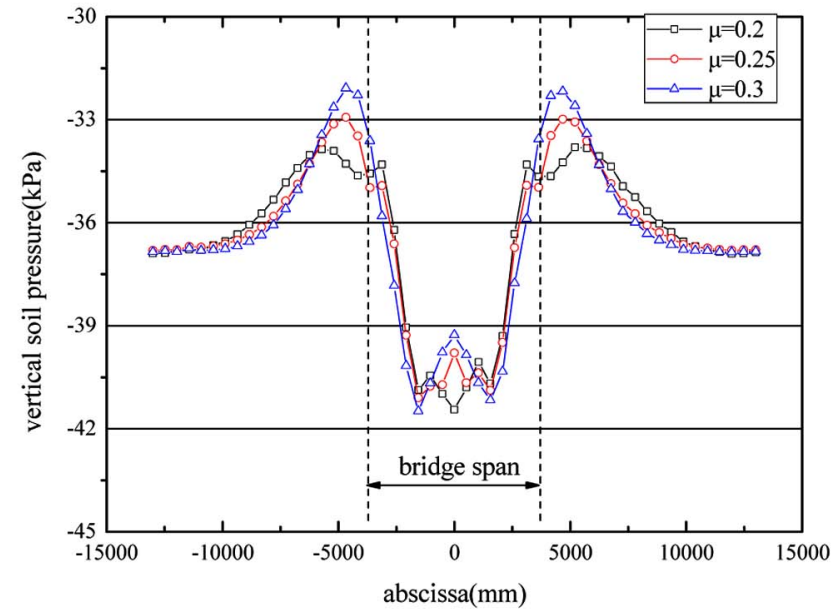

Poisson's ratio is a ratio between lateral and vertical deformation of soil, which affects soil displacement. As can be

Fig. (17). Vertical soil pressure and displacement of different Poisson's ratios under dead load.
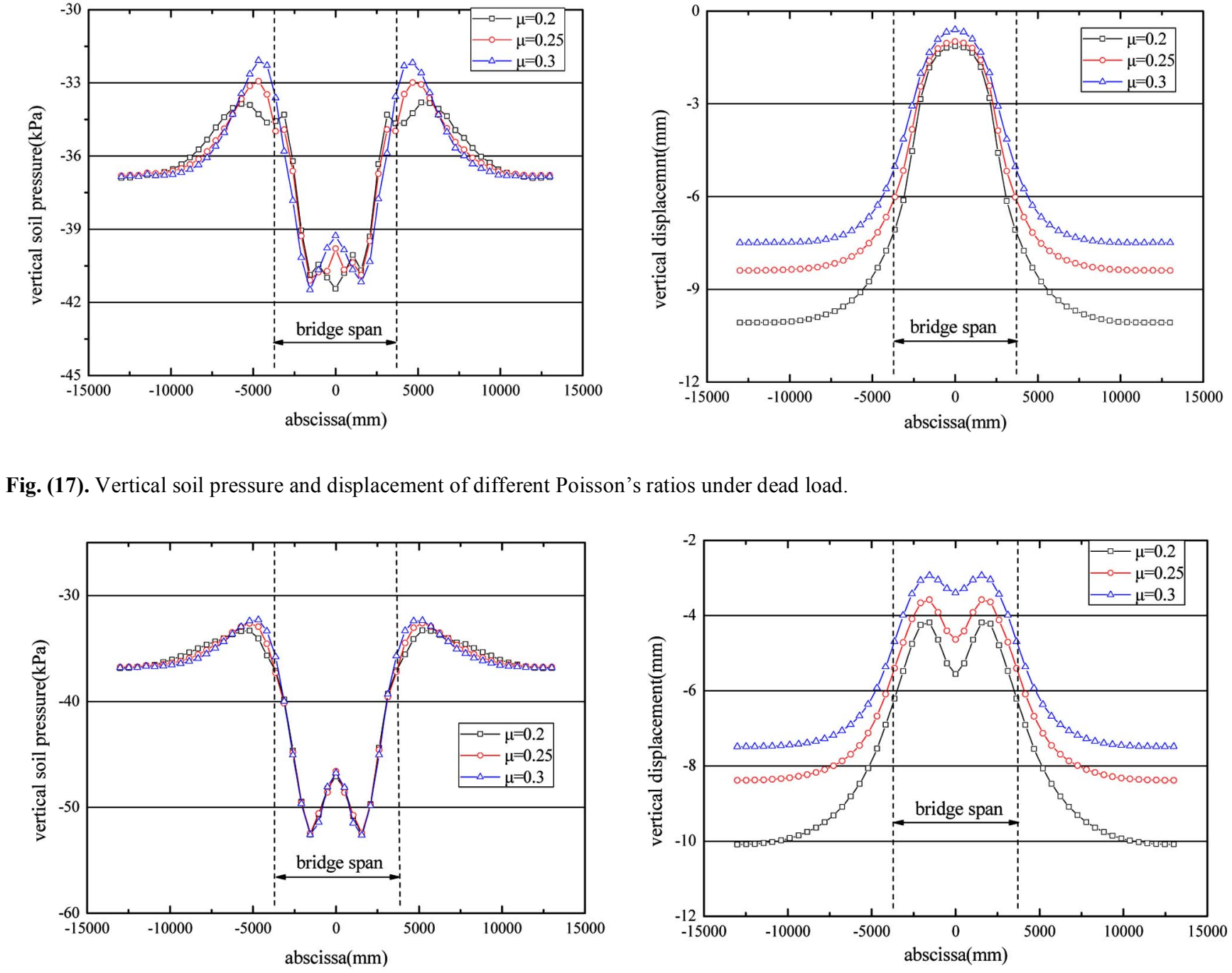

Fig. (18). Vertical soil pressure and displacement of different Poisson's ratios under vehicle load.
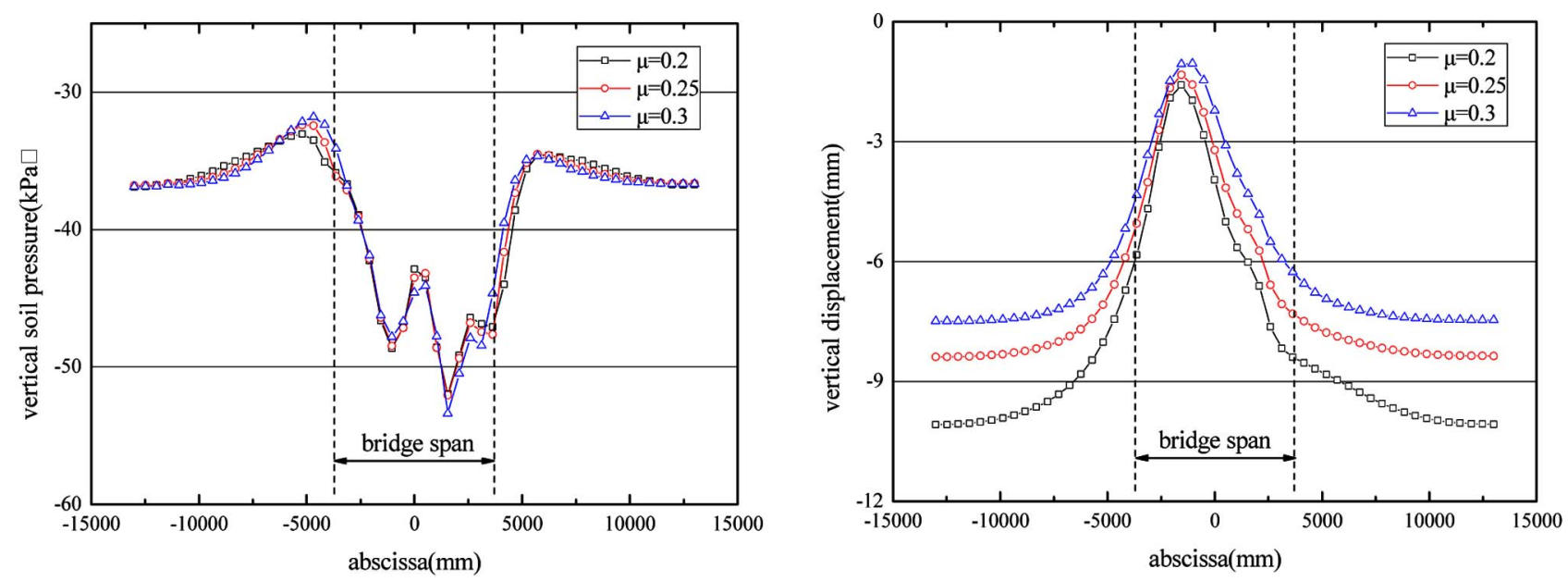

Fig. (19). Vertical soil pressure and displacement of different Poisson's ratios under deflective load. 
seen form Fig. (17), under dead load, horizontal deformation produced by same vertical deformation gets larger as Poisson's ratio increases, enhanced horizontal constraint leads to soil weight spreading to horizontal direction so that vertical soil pressure and displacement decrease slightly. Fig. (18 to 19) show that under vehicle load, the deformation increase of steel arch leads to smaller relative deformation, the difference of vertical soil pressure under different Poisson's ratios decreases. Soil with smaller Poisson's ratio has some positive effect in reducing soil pressure to the steel arch.

\section{CONCLUSION}

According to analysis of the soil-structure interaction for a buried corrugated steel arch bridge, the following conclusions are obtained:

(1) The stiffness of the arch bridge is relatively large and the result of soil-structure interaction is the vertical soil pressure which steel arch undertakes is larger than the soil weight on it. The soil pressure on the arch increases as the vehicle load acted. When the vehicle load localize at mid-span, the peak value of soil pressure approaches the code value. Asymmetric deformation occurs to the structure when there is deflective affection and the peak value of soil pressure is larger than that in mid-span load condition.

(2) The stiffness decrease of corrugated steel plate leads to larger deformation of the arch ring and positive to the soil-structure interaction. The vertical soil pressures on the steel arch are all reduced under the three different loading conditions.

(3) Larger elastic modulus of backfill soil leads to smaller soil displacement and is positive to the soil-structure interaction. So better soil should be chosen and compaction quality should be guaranteed.

(4) Larger internal friction angle increase the difference of soil pressure within and outside the span and has slightly negative effect to the soil-structure interaction. Smaller
Poisson's ratio increases soil displacements slightly, but has some positive effect in reducing soil pressure to the steel arch.

\section{ACKNOWLEDGEMENTS}

This research was supported by National Natural Science Foundation of China (50878016).

\section{REFERENCES AND NOTES}

[1] B. D. Liu, H. Yin, Z. M. Feng, Q. L. Wang, "Mechanics Behavior of Buried Corrugated Steel Arch Bridge Based on Soil-Steel Interaction Mode During Construction”, J Beijing Jiaotong University, vol. 33, no.4, pp.65-68, 2009.

[2] H. S. Yang and G. Z Xu, "Application of Corrugated Steel Pipe Culvert in Highway A30", Shanghai Highway, no.4, pp.30-32, 2006.

[3] C. W. Chen, "Corrugated Steel Structure and Its Application in Highway Engineering”, Highway, no.7, pp.48-54, 2000.

[4] Z. Wang and S. Q. Lu, "Effects of variation of strength and deformation parameters on calculation results of FEM for soil engineering", Rock Soil Mechanics, vol.26, no.12, pp. 1892-1894, 2005.

[5] Z. M. Feng, B. D Liu and Q. L Wang, "Structural Analysis and Design of Buried Corrugated Steel Bridge and Culvert", $J$ China Foreign Highway, vol.29, no.6, pp.141-145, 2009.

[6] Y. F. Fang and X. J. Wen, "Finite Element Analysis of Embedded Steel Corrugated Pipe Structure", Urban Roads Bridges Flood Control, no.6, pp.120-123, 2007.

[7] Z. M. Feng, "Soil-Structure Interaction Analysis and Design Method Study of Buried Corrugated Steel Bridges", M.E. thesis, Beijing Jiaotong University, Beijing, 2009.

[8] L. Feng, "Mechanics Behavior about Buried Corrugated Steel Culverts considering Soil-structure Interaction", M.E. thesis, Beijing Jiaotong University, Beijing, 2010.

[9] H. Yin, "Mechanics Behavior and Design about Buried Corrugated Steel Arch Bridge", M.E. thesis, Beijing Jiaotong University, Beijing, 2008.

[10] JTG D60-2004, "General Code for Design of Highway Bridges and Culverts", China Communications Press. Beijing, 2004.

[11] CAN/CSA-S6-00, "Canadian Highway Bridge Design Code", Standards Council of Canada, Toronto, Ontario, Canada, 2000.

[12] JTG D30-2004, "Specifications for Design of Highway Subgrades", China Communication Press, Beijing, 2004.

[13] GB_50021-2001, "Code for investigation of geotechnical engineering", China Architecture \& Building Press, Beijing, 2009. 